\title{
Epidemiology of Corona Virus Infection (COVID 19) among Health Care Workers in Benha University Hospital, Egypt
}

\author{
${ }^{1}$ Abeer E. Abd Elmaksoud, ${ }^{2}$ Hamasat A. Alnoury, ${ }^{3}$ Rehab S. EI Sawy, ${ }^{3}$ Mohamed Shaker, \\ ${ }^{4}$ Heba A. El Noury, and ${ }^{1}$ Eman Agwa \\ ${ }^{1}$ Public health and Community Medicine Department, ${ }^{2}$ Clinical and Chemical Pathology \\ Department, ${ }^{3}$ Chest Diseases and Tuberculosis Department, ${ }^{4}$ Pharmacology Department, \\ Faculty of Medicine, Benha University, Egypt
}

Submission Date: 21-03-2021

Revision Date: 27-05-2021

Acceptance Date: 27-05-2021

\begin{abstract}
Background: COVID-19 has become an important public health issue in the world. Health care workers (HCWs) are at high risk of infection contributing to further spread. Objectives: to describe the clinical manifestations, treatment lines of COVID-19 among HCWs and to compare infection control measures between cases and controls. Method: This case control study was conducted upon 184 confirmed infected HCWs with COVID-19 and equal number of healthy controls in Benha university hospitals, from April 6 to October 15, 2020. Data were collected by a structured questionnaire together with laboratory results and treatment received. Infection prevention and controls measures were compared between cases and control HCWs. Results: Among 184 patients, $27.8 \%$ of cases had pneumonia. The most common symptoms were bone pain (86.4\%). There were significant differences between cases and controls regarding following hand hygiene practice, knowing five moments of hand hygiene and using personal protective equipment (PPE). Conclusions: The majority of COVID-19 cases are mild. Lack of use of PPE and lack of hand hygiene practice were among risk factors of infection.
\end{abstract}

Keywords: COVID-19; HCWs; PCR; clinical characteristics; risk factors.

Corresponding author: Eman Agwa $\quad$ E mail: eman.agwa@fmed.bu.edu.eg

\section{Introduction}

In early December 2019, the first pneumonia cases of unknown origin were identified in Wuhan. It has been currently named severe acute respiratory syndrome coronavirus (SARS-CoV-2), which causes COVID-19. ${ }^{1}$ WHO announced COVID-19 outbreak a pandemic on March 11, 2020. ${ }^{2}$ As of July 22, 2020, more than 15 million cases of COVID-19 have been documented worldwide, with about 618000 deaths. ${ }^{3}$

There is human-to-human transmission through large droplets, contact and by touching surfaces contaminated by them and then touching the mouth, nose and eyes. ${ }^{4}$ The incubation period is from 2 to 14 days [median 5 days]. The common clinical presentations of covid-19 include fever, cough, headache, sore throat, fatigue, myalgia and breathlessness ${ }^{5}$, also there are smell/taste disorders. ${ }^{6}$

Laboratory-confirmed SARS-CoV-2 infection needs the detection of nucleic acid of the virus in respiratory samples through real-time reverse-transcription-polymerasechain-reaction (RT-PCR). ${ }^{7}$ The estimated median duration to negative RT-PCR tests of upper respiratory samples was 11 days. ${ }^{8}$ There may be increased CRP, lymphopenia, D-dimer might be elevated and hyperferritinemia in severe disease. ${ }^{9}$ Chest CT reveals ground glass opacities, 
infiltrates, and subsegmental consolidation. ${ }^{10}$

Till date, no confirmed treatment is available and so the treatment is supportive and symptomatic. The first step is adequate isolation to prevent transmission to others. ${ }^{5}$ Chloroquine may be effective in the early stage of infection ${ }^{11}$, but no positive feedbacks were noticed after taking antiviral treatment with oseltamivir. ${ }^{12}$ Zithromycin has been used as adjunctive treatment to get antibacterial coverage, immunomodulatory and anti-inflammatory effects in the management of some viral respiratory tract infections. ${ }^{13}$ Patients taking anticoagulants had a decreased mortality as COVID-19 lead to disseminated intravascular coagulation. ${ }^{14}$ HCWs are essential workers and have the risk for exposure to patients or infectious materials. Also, HCWs might potentially have a role in hospital transmission. The extent of COVID-19 transmission and risk factors associated with infection in healthcare settings are unclear. Without enough protection, COVID-19 morbidity and mortality may be elevated among healthcare workers and their family.

Several studies have demonstrated the risk factors leading to COVID-19 acquisition by HCWs in healthcare settings. A leakage of PPE, long-time exposure to infected patients and inadequate training in infection prevention and control have been the most prominent causes. A survey study about the number of HCWs have been infected with or died from COVID-19 was done across 37 countries including Egypt from 22 July to 15 August 2020, a total of 750 infections and 56 deaths were reported in Egypt. ${ }^{15}$, $16,17,18$

The objectives are to: 1) describe clinical symptoms, lines of treatment of COVID-19 among HCWs in Benha university hospitals; and compare between cases with pneumonia versus no pneumonia 2) describe the effects of COVID-19 infections on blood levels of some mediators (as D-dimer, ferritin, C-reactive protein); and 3) compare infection control measures between cases and control.

\section{Method}

Study design and participants: this case control study that was conducted upon 184 confirmed infected HCWs with COVID-19 in Benha university hospitals, from April 6 (the first confirmed case of COVID-19) to October 15, 2020 (the last collected cases) by convenient sampling and an equal number of HCWs controls were selected by systematic random sample from the same hospital. The patients were assessed for symptoms, treatments received and duration until becoming negative by RT PCR.

A confirmed case was defined as a suspected case with the laboratory test for the COVID-19 from the respiratory specimens show positive result by RT-PCR assay. Asymptomatic case was defined as a confirmed case with normal body temperature or minor dis-comfort; symptomatic non pneumonia case was defined as a confirmed case with fever and/or respiratory symptoms, but no radiographic evidence of pneumonia while symptomatic pneumonia case was defined as a confirmed case with fever, respiratory symptoms and radiographic evidence of pneumonia. ${ }^{19}$

Data collection: the following data for cases were abstracted from patient's file. Both cases and control were phone interview to complete missed data. 1- personal data (age, sex, residence, occupation, smoking and other comorbidities) 2- clinical presentation of COVID-19 infection (severity of cases either having or not having pneumonia depending on clinical diagnosis and chest imaging, fever, duration of fever, cough, duration of cough, loss of smell, bone pain, fatigue, headache, rhinorrhea, dyspnea, vomiting, diarrhea and 
Table (1): Socio -demographic characteristics and comorbidity of COVID19 cases

\begin{tabular}{|c|c|c|c|}
\hline \multirow{2}{*}{\multicolumn{2}{|c|}{$\begin{array}{l}\text { Socio-demographic and } \\
\text { clinical characteristics }\end{array}$}} & \multicolumn{2}{|c|}{$\begin{array}{c}\text { Total } \\
\text { no= }=184\end{array}$} \\
\hline & & No & $\%$ \\
\hline \multirow{2}{*}{ Sex } & Male & 105 & 57.1 \\
\hline & Female & 79 & 42.9 \\
\hline Age (years) & \multicolumn{3}{|c|}{$\begin{array}{c}\text { Mean } \pm \text { SD }(\text { Range }) \\
27.21 \pm 4.9(20-45)\end{array}$} \\
\hline \multirow{2}{*}{ Residence } & Urban & 85 & 46.2 \\
\hline & Rural & 99 & 53.8 \\
\hline \multirow{2}{*}{ Occupation } & Doctor & 106 & 57.6 \\
\hline & Nurse & 78 & 42.4 \\
\hline \multicolumn{2}{|c|}{ Cigarette smoking } & 15 & 8.2 \\
\hline \multirow[t]{2}{*}{ Comorbidities } & $\begin{array}{l}\text { Chronic lung } \\
\text { diseases }\end{array}$ & 22 & 12.0 \\
\hline & Cancer & 1 & 0.5 \\
\hline
\end{tabular}

throat congestion), site of isolation. 3-

Results of laboratory investigations (C reactive protein, ferritin, $\mathrm{D}$ dimer, hemoglobin, lymphocytes, white blood cells, platelets), blood group and chest CT. 4-Treatment received (antibiotics, vitamins, oral anticoagulants, Tamiflu and chloroquine). 5- Infection prevention and controls factors (take infection control practices in hospital, follow hand hygiene practice, know five moments of hand hygiene $\{1$ : before touching a patient, 2: before clean/aseptic procedure, 3: after body fluid exposure risk, 4: after touching a patient, 5: after touching the patient surroundings $\}$, availability of PPE, use PPE and availability of soap and water). ${ }^{19,} 20,21$, $22,23,24,25$

Statistical analysis: The collected data were tabulated and analyzed using the Statistical Package for Social Science, version 16.0 for windows, (SPSS Inc, Chicago,IL). Categorical data were summarized as frequency and proportion. Chi-square test and Fishers exact test were used as tests of significance. A P-value $\leq$ 0.05 was considered statistically significant.

Ethical consideration: An informed written consent was obtained from the participants, it included data about objectives, methods, benefits, expected harms and confidentiality of data. An approval from the Research Ethics Committee in Benha Faculty of Medicine was obtained to conduct this work (RC 3-4-2021).

\section{Results}

This study included 184 confirmed infected HCWs with COVID-19 their age ranged between 20 and 45 years. The males constituted $57.1 \%$ of the studied group, $53.8 \%$ of cases were from rural areas, $57.6 \%$ of the infected cases were doctors, $8.2 \%$ were cigarette smokers and $12.0 \%$ of the cases have chronic lung disease (Table $1)$.

There was statistically significant difference between cases and controls regarding following hand hygiene practice, knowing five moments of hand hygiene and using personal protective equipment $(\mathrm{P} \leq$ 0.05) (Table 2).

More than one-fourth (27.8\%) of cases were suffering from pneumonia. $80.4 \%$ of COVID-19 cases had fever, of them $39.2 \%$ had body temperature $>39 \mathrm{C}$ and ranged between 1 and 14 days. This study demonstrated that $77.2 \%$ of COVID-19 cases had cough that ranged between 1 and 30 days. Infected HCWs were suffering from loss of smell (49.5\%), bone pain $(86.4 \%)$, fatigue $(64.7 \%)$, headache $(53.8 \%)$, dyspnea $(17.4 \%)$, rhinorrhea (9.2\%), diarrhea (66.8\%), vomiting (21.2) and throat congestion $(31.5 \%)$. The duration of symptoms ranged between 2 and 30 days. There were $84.8 \%$ of cases had history of contact to cases with COVID-19 and duration between contact and occurrence of illness ranged between 2 and 7 days. The number of days to convert negative ranged between 7 and 35 days. There was statistically significant difference between symptomatic cases without pneumonia and symptomatic cases with pneumonia regarding fever, loss of 
Table (2): Comparison between cases and control regarding infection control practices

\begin{tabular}{|c|c|c|c|c|c|c|c|}
\hline \multirow{2}{*}{\multicolumn{2}{|c|}{ Infection control practices }} & \multicolumn{2}{|c|}{ Cases $(n=184)$} & \multicolumn{2}{|c|}{ Controls $(n=184)$} & \multirow[t]{2}{*}{ Test $\chi^{2}$} & \multirow{2}{*}{$\mathbf{P}$} \\
\hline & & No & $\%$ & No & $\%$ & & \\
\hline \multicolumn{2}{|c|}{$\begin{array}{l}\text { Taking infection control practices in } \\
\text { hospital }\end{array}$} & 93 & 49.7 & 94 & 50.3 & 0.011 & 0.91 \\
\hline \multicolumn{2}{|c|}{ Follow hand hygiene practice } & 110 & 42.3 & 150 & 57.7 & 20.96 & $<0.001$ \\
\hline \multirow{5}{*}{$\begin{array}{l}\text { know five moments } \\
\text { of hand hygiene }\end{array}$} & 1 moment & 10 & 66.7 & 5 & 33.3 & \multirow{5}{*}{25.97} & \multirow{5}{*}{$<0.001$} \\
\hline & 2 moments & 56 & 70.0 & 24 & 30.0 & & \\
\hline & 3 moments & 42 & 55.3 & 34 & 44.7 & & \\
\hline & 4 moments & 40 & 40.8 & 58 & 59.2 & & \\
\hline & 5 moments & 36 & 36.4 & 63 & 63.6 & & \\
\hline \multirow{2}{*}{$\begin{array}{l}\text { Use personal } \\
\text { protective equipment }\end{array}$} & Always & 93 & 43.5 & 121 & 56.5 & \multirow{2}{*}{8.75} & \multirow{2}{*}{0.003} \\
\hline & Sometimes & 91 & 59.1 & 63 & 40.9 & & \\
\hline \multicolumn{2}{|c|}{$\begin{array}{l}\text { Availability of personal protective } \\
\text { equipment }\end{array}$} & 127 & 48.3 & 136 & 51.7 & 1.07 & 0.299 \\
\hline \multicolumn{2}{|c|}{ Availability of soap and water } & 125 & 47.9 & 136 & 52.1 & 1.59 & 0.207 \\
\hline
\end{tabular}

Table (3): Comparison between cases with pneumonia and cases without pneumonia regarding clinical manifestations of COVID-19

\begin{tabular}{|c|c|c|c|c|c|c|}
\hline \multirow[t]{2}{*}{ Severity of cases } & \multicolumn{2}{|c|}{$\begin{array}{l}\text { Symptomatic cases } \\
\text { without pneumonia }\end{array}$} & \multicolumn{2}{|c|}{$\begin{array}{l}\text { Symptomatic cases } \\
\text { with pneumonia }\end{array}$} & \multirow[t]{2}{*}{ Test $\chi^{2}$} & \multirow[t]{2}{*}{$\mathbf{P}$} \\
\hline & No & $\%$ & No & $\%$ & & \\
\hline Fever & 98 & 73.1 & 50 & 100.0 & FET* & $<0.001$ \\
\hline Cough & 99 & 73.9 & 43 & 86.0 & 3.036 & 0.081 \\
\hline Loss of smell & 49 & 36.6 & 42 & 84.0 & 32.774 & $<0.001$ \\
\hline Bone pain & 118 & 88.1 & 41 & 82.0 & 1.139 & 0.286 \\
\hline Fatigue & 87 & 64.9 & 32 & 64.0 & 0.014 & 0.907 \\
\hline Headache & 67 & 50.0 & 32 & 64.0 & 2.871 & 0.091 \\
\hline Dyspnea & 17 & 12.7 & 15 & 30.0 & 7.597 & 0.006 \\
\hline Rhinorrhea & 9 & 6.7 & 8 & 16.0 & 3.742 & 0.053 \\
\hline Diarrhea & 82 & 61.2 & 41 & 82.0 & 7.113 & 0.008 \\
\hline Vomiting & 32 & 23.9 & 7 & 14.0 & 2.128 & 0.145 \\
\hline Throat congestion & 50 & 37.3 & 8 & 16.0 & 7.663 & 0.006 \\
\hline \multirow{3}{*}{\multicolumn{3}{|c|}{$\begin{array}{l}\text { *Fisher Exact test } \\
\text { smell, dyspnea, diarrhea and throat } \\
\text { congestion }(\mathrm{P} \leq 0.05) \text { (Table } 3) \text {. } \\
\text { The laboratory findings of COVID-19 cases } \\
\text { were: } 32.6 \% \text { had increased CRP, } 15.2 \% \\
\text { had increased ferritin, } 4.9 \% \text { had increased } \\
\mathrm{D} \text { dimer, } 87.0 \% \text { had normal hemoglobin, } \\
18.5 \% \text { had decreased WBCs, } 31.5 \% \text { had } \\
\text { decreased lymphocytes and } 9.2 \% \text { had } \\
\text { increased level of platelets. There was } \\
\text { statistically significant difference between } \\
\text { symptomatic cases without pneumonia and } \\
\text { symptomatic cases with pneumonia } \\
\text { regarding hemoglobin, WBCs, platelets and } \\
\text { blood group (P } \leq 0.05) \text { (Table 4). }\end{array}$}} & \multicolumn{4}{|c|}{$\begin{array}{l}\text { The treatment received were } 83.2 \%, 92.4 \% \text {, } \\
54.3 \%, 44.6 \% \text { and } 38.6 \% \text { antibiotic, } \\
\text { vitamins, chloroquine, Tamiflu and } \\
\text { received oral anticoagulants: respectively. } \\
\text { (Table 5). }\end{array}$} \\
\hline & & & \multicolumn{4}{|c|}{ Discussion } \\
\hline & & & \multicolumn{4}{|c|}{$\begin{array}{l}\text { Health care workers are at increased risk of } \\
\text { being exposed to viruses within hospitals } \\
\text { but can also be a source of transmission by } \\
\text { introducing a virus into their hospital. In the } \\
\text { current study, a total of } 184 \text { confirmed } \\
\text { infected HCWs with COVID } 19 \text { during } \\
\text { April } 6 \text { to October } 15,2020 \text { was reported. }\end{array}$} \\
\hline
\end{tabular}


Table (4): Comparison between cases with pneumonia and cases without pneumonia according to laboratory findings

\begin{tabular}{|c|c|c|c|c|c|c|c|}
\hline \multicolumn{2}{|c|}{ Severity of cases } & \multicolumn{2}{|c|}{$\begin{array}{l}\text { Symptomatic } \\
\text { cases without } \\
\text { pneumonia }\end{array}$} & \multicolumn{2}{|c|}{$\begin{array}{l}\text { Symptomatic } \\
\text { cases with } \\
\text { pneumonia }\end{array}$} & \multirow[t]{2}{*}{ Test $\chi^{2}$} & \multirow[t]{2}{*}{$\mathbf{P}$} \\
\hline & & No & $\%$ & No & $\%$ & & \\
\hline \multirow{3}{*}{$\begin{array}{l}\text { C reactive } \\
\text { protein }\end{array}$} & Normal & 9 & 6.7 & 9 & 18.0 & \multirow{3}{*}{5.880} & \multirow{3}{*}{0.053} \\
\hline & Increased & 43 & 32.1 & 17 & 34.0 & & \\
\hline & Not done & 82 & 61.2 & 24 & 48.0 & & \\
\hline \multirow{2}{*}{ Ferritin } & Increased & 19 & 14.2 & 9 & 18.0 & \multirow{2}{*}{0.412} & \multirow{2}{*}{0.521} \\
\hline & Not done & 115 & 85.8 & 41 & 82.0 & & \\
\hline \multirow{2}{*}{ D dimer } & Increased & 9 & 6.7 & 0 & 0.0 & \multirow{2}{*}{ FET* } & \multirow{2}{*}{0.116} \\
\hline & Not done & 125 & 93.3 & 50 & 100.0 & & \\
\hline \multirow{2}{*}{ Hemoglobin } & Normal & 110 & 82.1 & 50 & 100.0 & \multirow{2}{*}{ FET* } & \multirow{2}{*}{$<0.001$} \\
\hline & Increased & 24 & 17.9 & 0 & 0.0 & & \\
\hline \multirow{4}{*}{$\begin{array}{l}\text { White blood } \\
\text { cells }\end{array}$} & Normal & 85 & 63.4 & 41 & 82.0 & \multirow{4}{*}{$11.888^{*}$} & \multirow{4}{*}{0.006} \\
\hline & Increased & 17 & 12.7 & 0 & 0.0 & & \\
\hline & Decreased & 25 & 18.7 & 9 & 18.0 & & \\
\hline & Not done & 7 & 5.2 & 0 & 0.0 & & \\
\hline \multirow{4}{*}{ Lymphocytes } & Normal & 60 & 44.8 & 24 & 48.0 & \multirow{4}{*}{2.866} & \multirow{4}{*}{0.413} \\
\hline & Increased & 26 & 19.4 & 9 & 18.0 & & \\
\hline & Decreased & 41 & 30.6 & 17 & 34.0 & & \\
\hline & Not done & 7 & 5.2 & 0 & 0.0 & & \\
\hline \multirow{2}{*}{ Platelets } & Normal & 117 & 87.3 & 50 & 100.0 & \multirow{2}{*}{$\mathrm{FET}^{*}$} & \multirow{2}{*}{0.007} \\
\hline & Increased & 17 & 12.7 & 0 & 0.0 & & \\
\hline \multirow{4}{*}{ Blood groups } & A & 42 & 31.3 & 24 & 48.0 & \multirow{4}{*}{$34.417 *$} & \multirow{4}{*}{$<0.001$} \\
\hline & B & 25 & 18.7 & 22 & 44.0 & & \\
\hline & $\mathrm{AB}$ & 33 & 24.6 & 4 & 8.0 & & \\
\hline & $\mathrm{O}$ & 34 & 25.4 & 0 & 0.0 & & \\
\hline
\end{tabular}

*Fisher Exact test

In a study conducted between June 1 st and 14th, 2020, at the gastroenterological service of Al-Manial University Hospital, 74 HCWs were tested using RT-PCR. Of the $74 \mathrm{HCWs}, 10$ tested positive by RTPCR $(13.5 \%) .^{26}$

Previous studies reported variable number of infections among HCWs in developed countries. In a study conducted on 1353 HCWs in Dutch, found that $86(6 \%)$ tested positive for SARS-CoV-2 via nasal swab. ${ }^{27}$ Higher rates of infection of HCWs were observed in studies from the United Kingdom and Spain in March 2020, where 282/1533symptomatic HCWs (18\%) and $791 / 2085(38 \%)$ were confirmed to be infected by SARS-CoV-2infection via RTPCR, respectively. ${ }^{28,29}$

In this work only $12.5 \%$ of cases have comorbidities, most of the cases were mild as evidenced by relatively low rates of cases with pneumonia (27.8), fever was reported in $80.4 \%$ of cases, while $77.2 \%$ of cases had cough, $64.7 \%$ of cases had fatigue. Leukopenia and lymphopenia were noticed in $18.5 \%$ and $31.5 \%$ respectively. Creactive protein was increased in $32.6 \%$ of cases. The median duration to convert negative was 21 days by (RT- PCR).

These results are quite different than reported in a retrospective study conducted in Shanghai from Jan 20 to Feb 6, 2020, the study enrolled 249 patients of confirmed 
Table (5): Comparison between cases with pneumonia and cases without pneumonia regarding treatment

\begin{tabular}{|c|c|c|c|c|c|c|c|}
\hline \multirow{2}{*}{\multicolumn{2}{|c|}{ Severity of cases }} & \multicolumn{2}{|c|}{$\begin{array}{l}\text { Symptomatic cases } \\
\text { without pneumonia } \\
(134)\end{array}$} & \multicolumn{2}{|c|}{$\begin{array}{c}\text { Symptomatic } \\
\text { cases with } \\
\text { pneumonia (50) } \\
\end{array}$} & \multirow[t]{2}{*}{ Test $\chi^{2}$} & \multirow[t]{2}{*}{$\mathbf{P}$} \\
\hline & & No & $\%$ & No & $\%$ & & \\
\hline \multirow{3}{*}{$\begin{array}{l}\text { Site of } \\
\text { isolation }\end{array}$} & Hospital & 73 & 54.5 & 32 & 64.0 & \multirow{3}{*}{41.261} & \multirow{3}{*}{$<0.001$} \\
\hline & Home & 52 & 38.8 & 0 & 0.0 & & \\
\hline & Combined & 9 & 6.7 & 18 & 36.0 & & \\
\hline \multicolumn{2}{|c|}{ Antibiotics } & 118 & 88.1 & 35 & 70.0 & 8.477 & 0.004 \\
\hline \multicolumn{2}{|c|}{ Vitamins } & 127 & 94.8 & 43 & 86.0 & FET* $^{*}$ & 0.061 \\
\hline \multicolumn{2}{|c|}{ Chloroquine } & 68 & 50.7 & 32 & 64.0 & 2.578 & 0.108 \\
\hline \multicolumn{2}{|c|}{ Tamiflu } & 57 & 42.5 & 25 & 50.0 & 0.821 & 0.365 \\
\hline \multicolumn{2}{|c|}{ Oral anticoagulants } & 54 & 40.3 & 17 & 34.0 & 0.61 & 0.435 \\
\hline
\end{tabular}

*Fisher Exact test

COVID-19. It showed that $36.1 \%$ of cases had one or more coexisting chronic medical conditions. The most common symptoms in COVID-19 patients were fever $87.1 \%$, cough $36.5 \%$ and fatigue $15.7 \%$. Leukopenia and lymphopenia were observed in $28.9 \%$ and $47.4 \%$ of the patients, respectively. C-reactive protein (CRP) was elevated in more than half of the patients. Radiological lesions were observed in $65.7 \%$ of patients. The median duration to negative by RT-PCR tests of upper respiratory tract samples was 11 days $^{8}$, however, in retrospective, multicentre cohort study conducted on 191 patients from Jinyintan Hospital and Wuhan Pulmonary Hospital (Wuhan, China), found that the median duration of viral shedding was 20 days in survivors. The longest observed duration of viral shedding in survivors was 37 days. ${ }^{30}$

In addition, during February 12 April 9, 2020, a total of 9,282 United states health care providers (HCPs) with confirmed COVID-19 had been reported. The median age of HCP patients was 42 years, $73 \%$ were female which exceeded that stated in this study mean age was 27.2 years, $42.9 \%$ were female. About 1,423 (15\%) HCP patients who reported contact with a laboratory-confirmed COVID-19 patient less than reported in this study, $84.4 \%$ reported contact to COVID-19 patients. Two thirds $(66 \%)$ reported muscle aches less than stated here $86.4 \%$. However, $65 \%$ reported headache higher than reported in that study $53.8 \%$, $90 \%$ of cases were not hospitalized higher than reported in this study $57.1 \%$ only hospitalized. ${ }^{16}$

A search was run in the PubMed and Web of Science electronic databases for articles on COVID-19 between February 24, 2020, March 1, 2020, only 5 retrospective clinical studies had met the inclusion criteria. A total of 1556 hospitalized patients with COVID-19, rhinorrhea was rare (4\%) that near to finding of this study $9.2 \%$ had rhinorrhea. $^{22}$

The results demonstrated that $49.5 \%$ of infected HCWs had loss of smell. According to recent studies in various countries, the smell and taste is common clinical finding in confirmed cases of COVID-19 disease with a range of frequency from $19.4 \%$ to $88 \%$ of individuals. $^{31}$

In this study there was statistically significant difference between severity of infection and blood group as $48 \%$ of symptomatic cases with pneumonia were of blood group A and most of cases of COVID-19 were in blood group A. This result is similar to study conducted in Wuhan on 1775 with COVID-19, the results 
showed that blood group A was associated with a higher risk for acquiring COVID-19 compared with non-A blood groups, whereas blood group $\mathrm{O}$ was associated with a lower risk for the infection compared with non-O blood groups. ${ }^{32}$

In the current study $44.6 \%$ and $83.2 \%$ of cases received antiviral drugs and antibiotics therapy respectively. That were incompatible with case series of 99 hospitalized patients with COVID-19 infection from Wuhan, antiviral therapy was given to $75 \%$ of the patients. ${ }^{5}$ Also, in study conducted in China between December 11, 2019 and January 29, 2020 that enrolled 1099 patients and the data were obtained from medical record. The study showed that $(58 \%)$ of cases received antibiotics. $^{33}$

This study revealed that there was significant difference between cases and controls regarding use of personal protective equipment. As covering more of the body could provide better protection for HCWs. $^{34}$ Also, there was significant difference regarding following hand hygiene practice. This is supported by CDC guidelines for the public and health professionals to regularly wash their hands with ordinary soap and water for at least 20 seconds as it is considered the first-line preventive strategy of COVID-19 contamination. ${ }^{35}$

In this study, there was no significant difference between case and control regarding PPE availability this result is different than reported in a cross-sectional study in Ethiopia the study included 1228 HCWs that reported an overall shortage of PPE the majority (77\%) of HCWs reported that their hospital did not have adequate PPE. ${ }^{36}$

In survey study that was conducted in 33 hospitals in Sudan among workers in all radiology department reported that $75 \%$ of all workers had sufficient knowledge about hand hygiene and hand hygiene is embedded in their routine clinical practice. ${ }^{37}$ Also, in a cross-sectional study in 13 regions of Saudi Arabia among HCWs in radiology department reported that the majority of radiographic technologists reported wearing the recommended PPE regardless the patient infectious states during this pandemic and $80 \%$ of participant received frequent training about infection prevention and control at their health institutions while in this study only $50.8 \%$ of participant received training about infection prevention and control practice. ${ }^{38}$ The study main limitations were not all HCWs had done investigations thus the characteristics of COVID-19 infection were not properly demonstrated. Among HCW patients who reported contact with a confirmed COVID-19 patient in a health care setting, the type of this contact, including whether it was with a patient, other HCW, or visitor was not demonstrated.

\section{Conclusion}

The results of this study reflected the frequency of different symptoms, investigations, and treatment lines of COVID-19 infection among HCWs in Benha university hospitals where bone pain and fever were the main symptoms. Antibiotic and vitamins were the main lines of treatment. The severity of COVID-19 infection was statistically significant related to site of isolation, antibiotics intake and blood group. Lack of use of PPEs and lack of hand hygiene practices were among risk factors of infection among cases. Lake of knowledge and practice of infection prevention and control among HCWs could increase the spread of COVID-19 and so there is need to strengthen infection prevention and control practice among HCWs.

\section{Recommendations}


Every effort is needed to ensure safety and health of heath care worker both at health care settings and the community. Surveillance is essential for monitoring the effect of COVID-19 infection and better implementation of infection prevention and control practices.

Conflict of interest: There is no conflict of interest.

Funding: This research received no specific grant from any funding agency in the public, commercial, or not-for-profit sectors.

Acknowledgement: The authors would like to thank all HCWs for their time and cooperation.

\section{References}

1. Singhal, T. (2020). A Review of Coronavirus Disease-2019 (COVID-19). Indian Journal of Pediatrics. 87(4): 281-286.

2. Okunlola, M. A., Lamptey, E., Senkyire, E. K., et al. (2020). Perceived Myths and Misconceptions about the Novel COVID-19 Outbreak SciMedicine Journal. 2(3): 108-117. 3. Nguyen, L. H., Drew, D. A., Graham, M. S., et al. (2020). Risk of COVID-19 among frontline health-care workers and the general community: a prospective cohort study. The Lancet Public Health. 5(9): 475-483.

4. Ren, S. Y ., Wang, W., Hao, Y., et al. (2020). Stability and infectivity of coronaviruses in inanimate environments. World Journal of Clinical Cases. 8(8): 13911399.

5. Jain, N., Choudhury, A., Sharma, J., et al. (2020). A review of novel coronavirus infection (Coronavirus Disease-19). Global Journal of Transfusion Medicine. 5(1): 22.

6. Dell'Era ,V., Farri, F., Garzaro, G., et al. (2020). Smell and taste disorders during COVID-19 outbreak: A cross-sectional study on 355 patients. Head \&Neck. 42(7): 1591-1596.

7. Corman, V. M., Landt, O., Kaiser, M., et al. (2020). Detection of 2019 novel coronavirus (2019-nCoV) by real-time RT-PCR. EuroSurveillance. 25(3): 2000045.
8. Chen, J., Qi, T., Liu, L., et al. (2020). Clinical progression of patients with COVID19 in Shanghai, China. Journal of Infection. 80(5): 1-6.

9. Huang, I., Pranata, R., Lim, M. A., et al. (2020). C-reactive protein, procalcitonin, Ddimer, and ferritin in severe coronavirus disease-2019: a meta-analysis. Therapeutic advances in respiratory disease. 14 : 1753466620937175.

10. Carotti, M., Salaffi, F., Sarzi-Puttini P., et al. (2020). Chest CT features of coronavirus disease 2019 (COVID-19) pneumonia: key points for radiologists. La radiologia medica. 125 : 636-646.

11. Singh, R. and Vijay, V. (2020). Chloroquine: A Potential Drug in the COVID19 Scenario. Transactions of the Indian National Academy of Engineering. 7: 1-12

12. Yousefifard, M., Zali, A., Ali, K. M., et al. (2020). Antiviral therapy in management of COVID-19: a systematic review on current evidence. Archives of Academic Emergency Medicine. 8(1): 45.

13. Pani, A., Lauriola, M., Romandini, A., et al. (2020). Macrolides and viral infections: focus on azithromycin in COVID-19 pathology. International Journal of Antimicrobial Agents. 56(2): 106053

14. Juan Simon Rico-Mesa, J. S., Rosas D, Ahmadian-Tehran, A., et al. (2020). The Role of Anticoagulation in COVID-19-Induced Hypercoagulability. Current Cardiology Reports. 22(7): 53.

15. Chersich M. F., Gray G., Fairlie L., et al. (2020). COVID-19 in Africa: care and protection for frontline healthcare workers. Globalization and Health, 16: 1-6.

16. Center for Disease Control and prevention. (2020). Characteristics of Health Care Personnel with COVID-19-United States, February 12-April 9, 2020. https://www. cdc. gov/mmwr/volumes/69/wr/pdfs/mm6915e6-H. Accessed: july 25,2020

17. Al Maskari, Z., Al Blushi, A., Khamis, F., et al. (2021). Characteristics of healthcare workers infected with COVID-19: A crosssectional observational study. International Journal of Infectious Diseases, 102: 32-36.

18. Erdem, H., and Lucey, D. R. (2021). Healthcare worker infections and deaths due to 
COVID-19: A survey from 37 nations and a call for WHO to post national data on their website. International Journal of Infectious Diseases. 102: 239.

19. Tian, S., Hu, N., Lou, J., et al. (2020). Characteristics of COVID-19 infection in Beijing. Journal of Infection. 80(4): 401-406.

20. Center for Disease Control and prevention. (2020). Interim Clinical Guidance for Management of Patients with Confirmed Coronavirus Disease (COVID-19). Available at https://www.cdc.gov/coronavirus/2019ncov/hcp/clinical-guidance-managementpatients.html. Accessed: July 20, 2020.

21. Liang, T. (2020). Handbook of COVID-19 prevention and treatment. The First Affiliated Hospital, Zhejiang University School of Medicine. Compiled According to Clinical Experience. 68

22. Lovato, A., and de Filippis, C. (2020). Clinical presentation of COVID-19: a systematic review focusing on upper airway symptoms. Ear, Nose and Throat Journal. 99(9): 569-576.

23. National Institutes of Health. (2020). COVID-19 Treatment Guidelines Panel. Coronavirus Disease 2019 (COVID-19) Treatment Guidelines. Available at https://www.covid19treatmentguidelines.nih.g ov/ . Accessed July 28, 2020.

24. World Health Organization. (2020). Protocol for assessment of potential risk factors for coronavirus disease 2019 (COVID19) among health workers in a health care setting, 23 March 2020 (No. WHO/2019nCoV/HCW_risk_factors_protocol/2020.3).

World Health Organization.

25. World Health Organization. (2006). Your Five Moments of Hand Hygiene. Available at https://www.who.int/gpsc/tools/Five_momen ts/en. Accessed April 2, 2020.

26. Kassem, A. M., Talaat, H., Shawky, S., et al. (2020). SARS-CoV-2 infection among healthcare workers of a gastroenterological service in a tertiary care facility. Arab Journal of Gastroenterology. 21(3): 151-155.

27. Kluytmans-van den Bergh, M. F., Buiting, A. G., Pas, S. D., et al. (2020). Prevalence and clinical presentation of HCWs with symptoms of coronavirus disease 2019 in 2 Dutch hospitals during an early phase of the pandemic. JAMA network open. 3(5) : e209673-e209673.

28. Keeley, A. J., Evans, C., Colton, H., et al. (2020). Roll-out of SARS-CoV-2 testing for healthcare workers at a large NHS Foundation Trust in the United Kingdom, March 2020. Eurosurveillance. 25(14) : 2000433.

29. Folgueira, M. D., Munoz-Ruiperez, C., Alonso-Lopez, M. A., et al. (2020). SARSCoV-2 infection in HCWs in a large public hospital in Madrid. Spain, during March 2020. medrxiv. Accessed January 20, 2021.

30. Zhou, F., Yu, T., Du, R., et al. (2020). Clinical course and risk factors for mortality of adult inpatients with COVID-19 in Wuhan, China: a retrospective cohort study. The lancet. 395(10229): 1054-1062.

31. Al-Ani, R. M. (2020). Smell and Taste Abnormalities due to COVID-19. Al-Anbar Medical Journal. 16(1): 1-2.

32. Zhao, J., Yang, Y., Huang, HP., et al. (2020). Relationship between the ABO blood group and the COVID-19 susceptibility. Clinical infectious disease. https://doi.org/10.1101/2020.03.11.2003109

6. Accessed: July 20, 2020

33. Guan, W. J., Ni, Z. Y., Hu, Y., et al. (2020). Clinical Characteristics of Coronavirus Disease 2019 in China. New England Journal of Medicine. 382(18): 1708-1720.

34. Tian, Z., Stedman, M., Whyte, M., et al. (2020). Personal protective equipment (PPE) and infection among healthcare workers-what is the evidence? International journal of clinical practice. 74(11): 13617.

35. Center for Disease Control and Prevention. How to protect yourself \& others; 2020. Available from: https://www.cdc.gov/ coronavirus/2019-ncov/prevent-getting-

sick/prevention.html. Accessed August21, 2020.

36. Deressa, W., Worku, A., Abebe, W., et al. (2020). Availability of personal protective equipment and satisfaction of healthcare professionals during COVID-19 pandemic in Ethiopia. medRxiv. Accessed January 15, 2021. 37. Elgyoum, A. M., Zidan, M. M., Alonazi, B., etal. (2020). Covid-19 Prevention and control: A Study of The Knowledge, Awareness And Attitude Towards The Disease Among Radiology Departments Staff In Sudan. 
Archives of the Balkan Medical Union. 55(3). 410-417.

38. Aljondi, R., Alghamdi, S. S., Abdelaziz, I., et al. (2020). Knowledge of COVID-19 infection control among healthcare workers in radiology departments in Saudi Arabia. Journal of Radiation Research and Applied Sciences. 110. 